\section{Hydrogen Cyanamide-induced Budbreak and Phytotoxicity in 'Redhaven' Peach Buds}

Jorge H. Siller-Cepeda ${ }^{1}$, Leslie H. Fuchigami, and Tony H.H. Chen Department of Horticulture, Oregon State University, Corvallis, OR 97331-2911

Additional index words. Prunus persica, ecodormancy, endodormancy, paradormancy, rest, quiescence, chilling requirement, Dormex

Abstract. The effects of hydrogen cyanamide $\left(\mathrm{H}_{2} \mathrm{CN}_{2}\right)$ on budbreak and phytotoxicity of l-year-old potted peach trees [Prunus persica (L.) Batsch. cv. Redhaven] over a wide range of concentrations at several stages of dormancy were studied. Endodormancy $\left(180^{\circ} \mathrm{GS}\right.$; degree growth stage) began on 1 Oct. Maximum intensity of endodormancy $\left(270^{\circ} \mathrm{GS}\right)$ was reached after the plants were exposed to 320 chill units on 1 Nov., and $50 \%$ of the buds were broken at 860 chill units on 1 Dec. Five concentrations of $\mathrm{H}_{2} \mathrm{CN}_{2}(0,0.125,0.25,0.5$, and $1.0 \mathrm{M})$ were applied on 1 and 15 Oct., 1 and 15 Nov., and 1 and 15 Dec. 1990. All concentrations promoted budbreak; however, percent budbreak and phytotoxicity depended on concentration and timing of application. The most effective concentration (greatest budbreak and lowest phytotoxicity) was $0.125 \mathrm{M} \mathrm{H}_{2} \mathrm{CN}_{2}$ on all treatment dates. Phytotoxicity was evident at all application dates but was greatest at the highest concentrations. Plants were most resistant to $\mathrm{H}_{2} \mathrm{CN}_{2}$ at maximum intensity of endodormancy. Hydrogen cyanamide-induced budbreak was highest during the later stages of endodormancy $\left(295\right.$ to $\left.315^{\circ} \mathrm{GS}\right)$. Treatments applied during the ecodormancy stage $\left(340^{\circ} \mathrm{GS}\right)$ inhibited and delayed budbreak and damaged buds and stems. Chemical name used: hydrogen cyanamide $\left(\mathrm{H}_{2} \mathrm{CN}_{2}\right.$, Dormex).

Dormancy is a phase of development that occurs annually in deciduous fruit trees and other temperate woody perennials (Saure, 1985). Release of dormancy requires a period of chilling temperatures during winter, followed by a rise in temperature in spring (Fuchigami et al., 1982; Richardson et al., 1974). A major obstacle to economic production of deciduous fruit trees in the subtropics and tropics is an insufficient period of chilling temperatures. Inadequate chilling may result in poor and uneven budbreak, reduced and delayed foliage development, sparse bloom, abnormal flower development, poor fruit set, and/or early growth cessation (Erez, 1987; Saure, 1985).

In the tropics, plants are prevented from entering endodormancy by cultural prac-

Received for publication 8 Oct. 1991. Accepted for publication $10 \mathrm{Feb} .1992$. Oregon Agricultural Experiment Station Paper no. 9719. This research was supported in part by the U.S.-Israel Binational Agricultural Research and Development fund (BARD no. 1343-87), and by a research agreement with SKW, Trostberg, Germany. We thank Patrick Breen, Anita Miller-Azarenko, and Shawn Mehlenbacher for their help in the preparation of this manuscript. The cost of publishing this paper was defrayed in part by the payment of page charges. Under postal regulations, this paper therefore must be hereby marked advertisement solely to indicate this fact.

'Present address: Research Center in Food and Development, Apartado Postal 1735, Hermosillo, Sonora 83000 Mexico. tices, usually by defoliation or withholding irrigation (Edwards, 1987). In the subtropics, budbreak is hastened after plants have entered dormancy by a combination of cultural practices and application of rest-breaking chemicals (Erez, 1987).

Although many chemical and physical treatments are known to break dormancy, only a few have proven useful under field conditions (Erez, 1987). Hydrogen cyanamide (Dormex, SKW, Trostberg AG, Germany) has been identified as one of the most effective dormancy-breaking agents in many deciduous plant species (Fuchigami and Nee, 1987). A major problem in using $\mathrm{H}_{2} \mathrm{CN}_{2}$ to artificially break dormancy, however, is determining when and at what concentration to apply the chemicals.

One characteristic common to most dormancy-breaking treatments is that they are effective only over a narrow range at nearlethal dosages (Erez, 1987; Fuchigami and Nee, 1987). Thus, variable effectiveness in overcoming dormancy and phytotoxicity is commonly encountered (Dozier et al., 1990; Wolak and Couvillon, 1976). Factors that contribute to the variable responses include: time of application (Fuchigami and Nee, 1987; Wolak and Couvillon, 1976), physiological stage of bud development (Fuchigami and Nee, 1987), nutritional status (Terblanche and Strydom, 1973), postapplication temperatures (Erez, 1987) and amount of chilling accumulated (Erez, 1979).

The objectives of this study were to: a) examine the effects of $\mathrm{H}_{2} \mathrm{CN}_{2}$ on budbreak of and phytotoxicity to 'Redhaven' peach trees at several times in the dormancy phases; and b) identify effective $\mathrm{H}_{2} \mathrm{CN}_{2}$ concentrations at several physiological stages in breaking dormancy.

One-year-old potted peach trees were used in this study. 'Redhaven' scions of current season's growth were grafted onto prune ( $P$. insititia cv. St. Julian A) rootstocks in early Feb. 1990. The graft union was placed for 2 weeks in a hot callusing pipe at $26 \mathrm{C}$ to promote callus formation. The grafted plants were then transferred into 4-liter pots containing 1 loam soil : 1 washed sand : 1 peat moss : 2 pumice rock (by volume). Plants were grown under natural conditions during spring and summer and pruned to a single stem in July. At the end of the growing pe-



Fig. 1. Percent budbreak of 'Redhaven' peach buds (control) after 4 weeks of forcing conditions, ${ }^{\circ} \mathrm{GS}$ calculation, and chilling unit accumulation from Aug.-Dec. 1990.

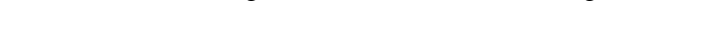




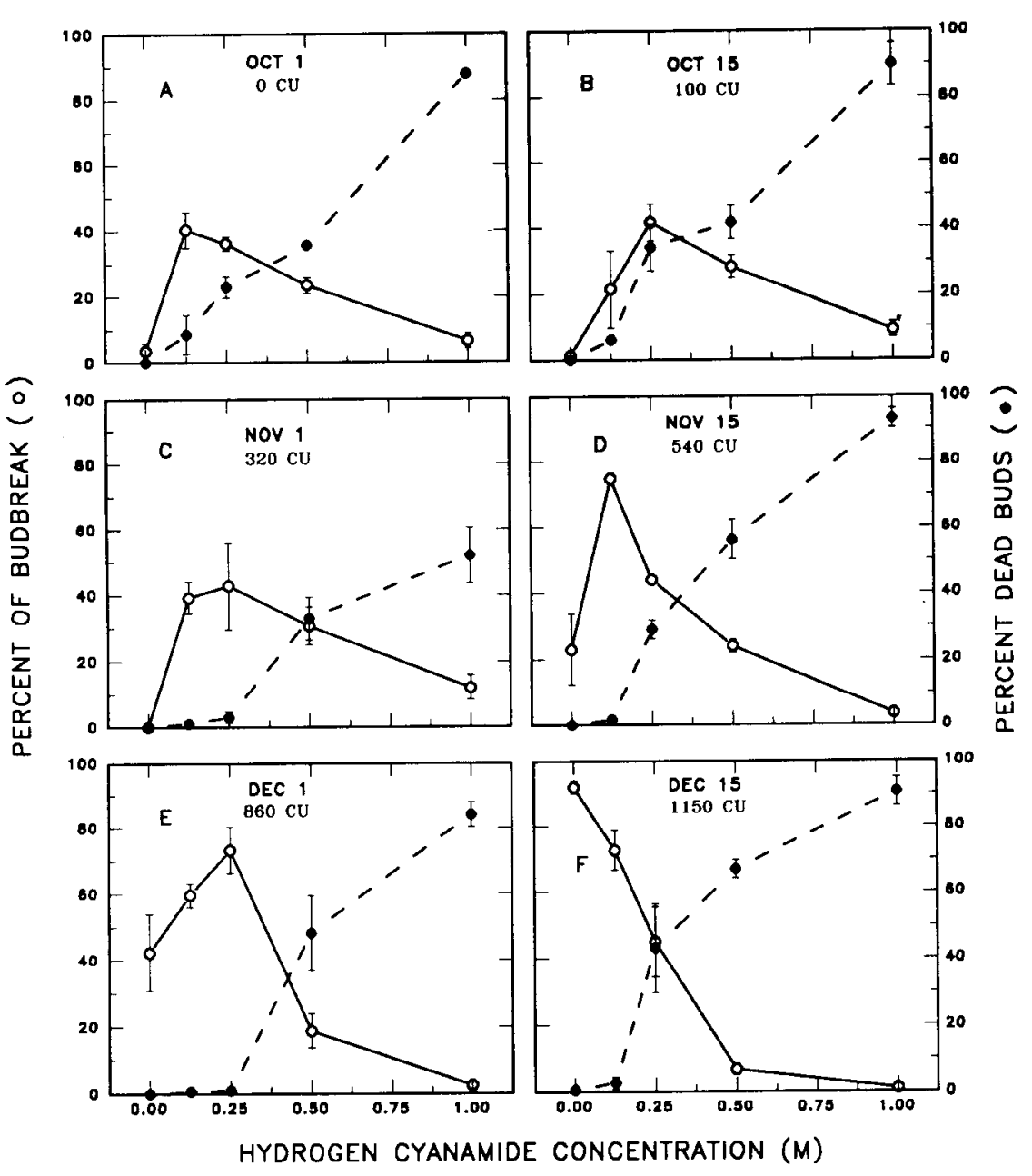

Fig. 2. Percent budbreak (-) and percent dead buds (- - -) in 'Redhaven' peach trees induced by hydrogen cyanamide sprayed at $0,0.125,0.25,0.5$, or $1.0 \mathrm{M}$ and applied on (A) 1 Oct. (0 chilling units; CUs); (B) 15 Oct. (100 CUs); (C) 1 Nov. (320 CUs); (D) 15 Nov. (540 CUs); (E) 1 Dec. (860 CUs); and (F) 15 Dec. (1150 CUs).

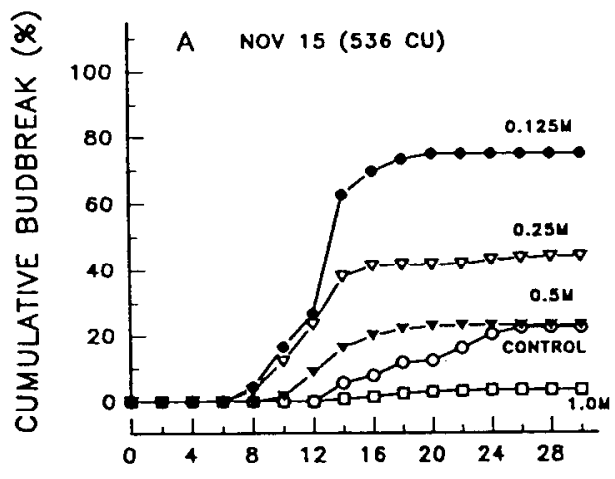

DAYS AFTER TREATMENT

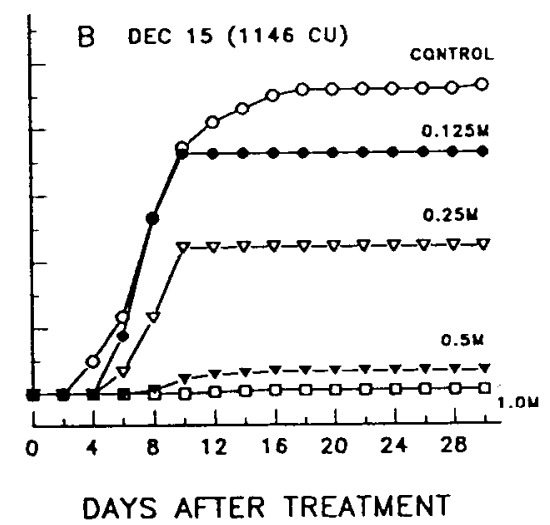

Fig. 3. Days to budbreak after treatment and cumulative percent budbreak of 'Redhaven' peach buds induced by hydrogen cyanamide sprayed at $0,0.125,0.25,0.5$, or $1.0 \mathrm{M}$, and applied on (A) 15 Nov. (540 chilling units; CUs); and (B) 15 Dec. (1150 CUs).

riod, plants averaged $1.5 \mathrm{~m}$ high and had $\approx 150$ lateral and four to eight terminal buds.

To determine the stage of dormancy after terminal bud set, 10 plants were manually defoliated at $\approx 2$-week intervals from 29 Aug.-1 Nov. (Fuchigami et al., 1982). Plants were defoliated, total buds were counted, and plants were moved to a greenhouse at $25 \pm$ $3 \mathrm{C} / 20 \pm 3 \mathrm{C}$ (day/night). High-pressure so-
To determine budbreak and phytotoxicity induced by $\mathrm{H}_{2} \mathrm{CN}_{2}$, trees were sprayed to runoff with distilled water (control) or $\mathrm{H}_{2} \mathrm{CN}_{2}$ solutions at $0.125,0.25,0.50$, and $1.0 \mathrm{M}$. Plants were treated and then moved into the greenhouse on: 1 and 15 Oct., 1 and 15 Nov., and 1 and 15 Dec. The total number of buds was counted before application of the treatments.

Rate and fraction of budbreak were expressed as the percentage of total buds that opened after 4 weeks in the greenhouse. Vegetative buds were considered open at stage 2 , i.e., visible swelling of two leaves, based on the Guerriero and Scalabrelli (1974) rating scale. Flower buds were considered open at the green calyx stage (calyx visibly green). Phytotoxicity was expressed as percent dead buds at the end of 4 weeks in the greenhouse.

Outside air temperatures were recorded with a hygrothermograph placed in a wooden shelter raised above the ground, adjacent to the plants. Chilling unit (CU) accumulation was calculated according to the model of Richardson et al. (1974). Chilling was considered-satisfied when $50 \%$ of the buds had broken after 4 weeks in the greenhouse (Weinberger, 1950).

Treatments were arranged in a completely randomized design with factorial arrangement for date of application and $\mathrm{H}_{2} \mathrm{CN}_{2}$ concentration. Percentage data were transformed into the square root of arcsin percentage before statistical analysis. SAS software was used to perform the statistical analysis (SAS Institute, Inc., Cary, N.C.). Data are presented as the mean of four single-plant replications $\pm \mathrm{SE}$.

Chilling has been shown to increase the intensity of endodormancy as well as to overcome endodormancy in many woody plant species (Fuchigami et al., 1982; Fuchigami and Nee, 1987; Saure, 1975). According to the Utah chilling accumulation model (Richardson et al., 1974), CUs started to accumulate in the field on 5 Oct. and continued through the end of December (Fig. 1 ). The percent budbreak increased greatly in mid-November, after 320 CUs had accumulated. Accumulation of CUs was rapid, and by $1 \mathrm{Dec}$. at $860 \mathrm{CUs}$, release from endodormancy was evident. Based on greenhouse forcing studies, the chilling requirement to overcome endodormancy in 'Redhaven' peach buds was fulfilled on $\approx 1$ Dec. with 860 CUs. Richardson et al. (1974) reported a similar value for the same cultivar.

Peach trees defoliated on 19 Aug. and 18 Sept. and placed in a greenhouse showed $\geq 60 \%$ and $50 \%$ budbreak, respectively, after 21 days (Fig. 1). The rapid rate and high percentage of budbreak of these plants suggest that they were still under paradormancy $\left(90^{\circ} \mathrm{GS}\right.$ to $\left.180^{\circ} \mathrm{GS}\right)$, rather than endodormancy (Fuchigami et al., 1982; Saure, 1985).

Endodormancy is generally considered to have started if artificial defoliation and/or decapitation of the shoots fails to cause budbreak (Fuchigami et al., 1982; Saure, 1985). Defoliation and greenhouse regrowth tests on 1 and 15 Oct. and 1 Nov. were followed by a significant reduction in percent budbreak 
Table 1. Analysis of variance of the effect of hydrogen cyanamide concentration and time of application on budbreak and phytotoxicity of 'Redhaven' peach buds.

\begin{tabular}{|c|c|c|c|c|c|}
\hline \multirow[b]{2}{*}{ Source of variation } & \multirow[b]{2}{*}{ df } & \multicolumn{2}{|c|}{ Budbreak } & \multicolumn{2}{|c|}{ Dead buds } \\
\hline & & MS & F & MS & F \\
\hline Hydrogen cyanamide & 4 & $4,098.7$ & - & $15,609.7$ & - \\
\hline $\begin{array}{l}\text { Time of application } \\
\text { Hydrogen cyanamide } \times\end{array}$ & 5 & 677.6 & -- & 788.0 & -- \\
\hline $\begin{array}{l}\text { time of application } \\
\text { Error }\end{array}$ & $\begin{array}{l}20 \\
80\end{array}$ & $\begin{array}{r}832.0 \\
66.7\end{array}$ & $12.4^{* *}$ & 212.9 & $4.0^{* *}$ \\
\hline
\end{tabular}

**Significant at $P=0.001$.

(Fig. 1), indicating that the plants had already acquired endodormancy $\left(180^{\circ} \mathrm{GS}\right)$ on 1 Oct. and maximum endodormancy $\left(270^{\circ}\right.$ GS) on 1 Nov. (Fuchigami et al., 1982). A similar reduction of budbreak with successive defoliation dates has been shown for 'Washington' peach trees (Lloyd and Couvillon, 1974).

Percent budbreak increased from $23 \%$ on 15 Nov. to $92 \%$ on 15 Dec., corresponding to 536 and 1146 CUs, respectively. Fifty percent budbreak was calculated to occur at $\approx 860$ CUs (Fig. 1). Under natural conditions, 50\% budbreak occurred on 5 Feb. 1991.

Comparing the results of previous reports on the effect of dormancy-breaking chemicals is difficult, because, generally, the endodormancy stage at application was not determined. Our study and others (Bracho et al., 1984; Erez, 1987; Fuchigami and Nee, 1987) indicate that the effects of $\mathrm{H}_{2} \mathrm{CN}_{2}$ on budbreak and phytotoxicity depend on concentration and timing (physiological stage of the bud). Other researchers have not considered the physiological status of buds, and this may be one of the reasons for the highly variable results in the effectiveness of $\mathrm{H}_{2} \mathrm{CN}_{2}$ in overcoming endodormancy (Dozier et al., 1990; Erez, 1987; Wolak and Couvillon, 1977).

Application of $\mathrm{H}_{2} \mathrm{CN}_{2}$ to peach plants from 1 Oct.-1 Dec. increased budbreak (Fig. 2 A-E). Budbreak on treated plants was observed 8 to 12 days after application (Fig. $3 \mathrm{~A})$. In general, the most effective concentration (most budbreak and least phytotoxicity) was $0.125 \mathrm{M} \mathrm{H}_{2} \mathrm{CN}_{2}$ on all treatment dates. Budbreak at 0.5 and $1.0 \mathrm{M} \mathrm{H}_{2} \mathrm{CN}_{2}$ was confined to the basal buds due to phytotoxicity of the upper buds.

At maximum endodormancy $\left(270^{\circ} \mathrm{GS}\right)$, higher $\mathrm{H}_{2} \mathrm{CN}_{2}$ concentrations were required to stimulate peach budbreak than earlier. Fuchigami and Nee (1987) showed that as the degree of endodormancy increased, correspondingly higher concentrations were required to break endodormancy in dogwood (Cornus sevicea L.) and crabapple (Malus sylvestris L). In our study, we found no differences in budbreak during the development of maximum endodormancy after treatment with $0.125,0.25$, and $0.5 \mathrm{M} \mathrm{H}_{2} \mathrm{CN}_{2}$ (Fig. 2 $\mathrm{B}$ and $\mathrm{C})$. At these stages, even the highest concentration enhanced budbreak, although it only stimulated the breaking of basal buds. In grapes (Vitis vinifera L.), concentrations $\geq 1$ m have been shown to stimulate bud- break of basal and latent buds and are used when renewal of old vines with bare cordons is needed (Bracho et al., 1984; Lavee et al., 1984). The greater tolerance of the lower buds to $\mathrm{H}_{2} \mathrm{CN}_{2}$ is probably related to the gradient of dormancy intensity down the shoot, with lower buds more dormant than those above (Paiva and Robitaille, 1978).

The highest percent budbreak was found during the late endodormancy period (295 to $315^{\circ} \mathrm{GS}$ ). However, phytotoxicity during this period was quite high $(80 \%$ to $90 \%)$ for all but the lowest concentration (Fig. $2 \mathrm{D}$ and E). Fernandez-Escobar and Martin (1987) reported that $\mathrm{H}_{2} \mathrm{CN}_{2}$ strongly inhibited flower bud development of peaches when applied at concentrations $>0.6 \mathrm{M}$. However, $\mathrm{H}_{2} \mathrm{CN}_{2}$ applied at 0.1 to $0.6 \mathrm{M}$ promoted vegetative growth when accumulated chilling hours were $<474$ CUs. In contrast, Dozier et al. (1990) reported that peach and nectarine trees responded linearly to $\mathrm{H}_{2} \mathrm{CN}_{2}$ levels applied on 15 Mar. after 650 CUs, with the highest budbreak at the $2 \%(0.5 \mathrm{M})$ rate.

Application of $\mathrm{H}_{2} \mathrm{C} \mathrm{N}_{2}$ after chilling satisfaction had no effect on promoting budbreak (Figs. 2F and 3B). Rather than enhancing budbreak, cyanamide reduced and delayed bud growth and injured the bud and stems. Similar results have been reported for other species when cyanamide was applied during ecodormancy (Fuchigami and Nee, 1987). It is likely that most of the variability in budbreak and toxicity found in this study can be attributed to the physiological status of the bud and the amount of chilling accumulated before the application. Furthermore, the variable results of others from field application of hydrogen $\mathrm{H}_{2} \mathrm{C} \mathrm{N}_{2}$ can be explained partially by differences in degree of dormancy of the plant. The physiological stage of the bud appears to be a critical juncture in defining the narrow limits between optimum and phytotoxic concentrations of the chemical treatments. A highly significant interaction of $\mathrm{H}_{2} \mathrm{CN}_{2}$ concentration and timing of application was found for budbreak and phytotoxicity (Table 1).

The results presented here suggest that: 1) $\mathrm{H}_{2} \mathrm{CN}_{2}$ is effective in overcoming endodormancy in unchilled as well as partially chilled peach trees; 2) timing and concentration of $\mathrm{H}_{2} \mathrm{CN}_{2}$ affect percent budbreak; 3) timing is a function of the dormancy stage of the buds; and 4) concentrations $\geq 0.5 \mathrm{M}$ are highly phytotoxic to peach buds.

\section{Literature Cited}

Bracho, E., J.O. Johnson, A.S. Wickes, L.A Lider, and R.J. Weaver. 1984. Using hydrogen cyanamide to promote uniform budbreak in $\mathrm{Ca}$ bernet Sauvignon in California, p. 11-14. In: R.J. Weaver (ed.). Proceedings of bud dormancy in grapevine. Potential and practical uses of hydrogen cyanamide on grapevine. Univ. of California, Davis.

Dozier, W.A., A.A. Powell, A.W. Caylor, N.R. McDaniel, E.L. Carden, and J.A. McGuire. 1990. Hydrogen cyanamide induces budbreak of peaches and nectarines following inadequate chilling. HortScience 25:1573-1575.

Edwards, G.R. 1987. Producing temperate-zone fruit at low latitudes: Avoiding rest and the chilling requirement. HortScience 22:1236-1240.

Erez, A. 1979. The effect of temperature on the activity of oil + dinitro-o-cresol sprays to break the rest of apple buds. HortScience 14:141-142.

Erez, A. 1987. Chemical control of budbreak. HortScience 22:1240-1243.

Fernandez-Escobar, R. and R. Martin. 1987. Chemical treatments for breaking rest in peach in relation to accumulated chilling. J. Hort. Sci. 62:457-661.

Fuchigami, L.H., C.J. Weiser, K. Kobayashi, R. Timmis, and L.V. Gusta. 1982. A degree growth stage $\left({ }^{\circ} \mathrm{GS}\right)$ model and cold acclimation in temperate woody plants, p. 93-116. In: P. Li and A. Sakai (eds.). Plant cold hardiness and freezing stress. Academic, New York.

Fuchigami, L.H. and C.C. Nee. 1987. Degree growth stage model and rest breaking mechanisms in temperate woody perennials. HortScience 22:836-845.

Guerriero, P.R. and G. Scalabrelli. 1974. Effect to dei trattamenti invernali con fitoregolatori sul germogliamento di seminzali di pesco in vivaio. Riv. Ortoflorofrutt. 57(5):350-359.

Lavee, S., Y. Shuhnan, and G. Nir. 1984. The effect of cyanamide on budbreak of grapevines Vitis vinifera, p. 17-29. In: R.J. Weaver (ed.). Proceedings of bud dormancy in grapevine: Potential and practical uses of hydrogen cyanamide on grapevine. Univ. of Calif., Davis.

Lloyd, D.A. and G.A. Couvillon. 1974. Effects of date of defoliation on flower and bud development in the peach Prunus persica (L.) Batsch. J. Amer. Soc. Hort. Sci. 99:514-517.

Paiva, E. and H.A. Robitaille. 1978. Breaking bud rest on detached apple shoots: Effects of wounding and ethylene. J. Amer. Soc. Hort. Sci. 103:101-104.

Richardson, E.A., S.D. Seeley, and D.R. Walker. 1974. A model for estimating the completion of rest for 'Redhaven' and 'Elberta' peaches. HortScience 9:331-332.

Saure, M.C. 1985. Dormancy release in deciduous fruit trees. Hort. Rev. 7:239-300.

Terblanche, J.H. and D.K. Strydom. 1973. Effect of autumnal nitrogen nutrition, urea sprays and a winter rest-breaking spray on budbreak and blossoming of young 'Golden Delicious' trees grown in sand culture. Deciduous Fruit Grower 23:8-14.

Weinberger, J.H. 1950. Prolonged dormancy of peaches. Proc. Amer. Soc. Hort. Sci.

Wolak, R.J. and G.A. Couvillon. 1976. Time of thiourea- $\mathrm{KNO}_{3}$ application on the rest requirement and bud development in 'Loring' peach. HortScience 11:400-402.

Wolak, R.J. and G.A. Couvillon. 1977. Post-bloom applications of thiourea and $\mathrm{KNO}_{3}$ fails to alleviate prolonged dormancy in peach trees. HortScience 12:123. 